American Journal of Animal and Veterinary Sciences 5 (3): 180-182, 2010

ISSN 1557-4555

(C) 2010 Science Publications

\title{
EIAV Effectiveness Detection by Nested PCR Comparing two Different Samples: PBMCs and Bronchoalveolar Wash
}

\author{
Elizangela Maira Dos Santos, Pedro Moreira Couto Motta, Marcos Bryan Heinemann, \\ Rômulo Cerqueira Leite, Helen Lima Del Puerto and Jenner Karlisson Pimenta Dos Reis \\ Department of Preventive Veterinary Medicine, Veterinary School, \\ Federal University of Minas Gerais, UFMG, 30123-970, Belo Horizonte, MG, Brazil
}

\begin{abstract}
Problem statement: Equine Infectious Anemia (EIA) is a chronic, relapsing infectious disease of horses caused by Equine Infectious Anemia Virus (EIAV). The objective of this experiment was compared EIAV effectiveness detection in Peripheral Blood Mononuclear Cells (PBMCs) and Bronchoalveolar wash (BAW) from naturally infected horses. Approach: Fifty seven DNA samples isolated from PBMCs and BAW of naturally infected animals were used for a nested PCR amplifying a $408 \mathrm{bp}$ gag gene fragment region. Equine Dermal cells (ED) infected and non infected by EIAV was used as nested PCR negative and positive control. Horses' blood samples were firstly tested as positive in Agar Gel Immunodiffusion Assay (AGID). Results: Results demonstrated 89\% (51/57) of gag gene amplification in PBMCs samples and only 47\% (27/57) of gag gene amplification in BAW samples. Conclusion: The nested PCR assay used in the present study detected more EIAV positive samples in PBMC than in BAW, indicating PBMCs as a reliable source for EIAV diagnosis.
\end{abstract}

Key words: Diagnosis, EIA, EIAV, nPCR and PBMCs

\section{INTRODUCTION}

Equine Infectious Anemia (EIA) is a horse disease caused by Equine Infectious Anemia Virus (EIAV), a retrovirus transmitted by bloodsucking insects. The control of EIA is made through the identification of infected animals by the serological tests ELISA and IDGA (Alvarez et al., 2007), but many factors contribute to inconsistent results with these tests that require confirmation using more specific techniques (Alvarez et al., 2007). Thus, the nested PCR technique is a sensitive diagnostic test for the detection of the virus in recent infections in which the immune response is still being built and those cases of neonatal infections, besides elucidating the inconclusive serological results (Issel and Cook, 1993; Langemeier et al., 1996). The main targets of EIAV replication in vivo are cells from the monocyte-macrophage lineage and the main tissue targets are the macrophages from spleen, liver, lymph nodes and lungs (Harrold et al., 2000). Preliminary data indicate that infection of blood monocytes by EIAV causes a non-productive infection and that differentiation of the infected monocytes into macrophages is necessary to trigger viral replication (Maury, 1994; Sellon et al., 1996) and macrophages are the major cell type found in bronchoalveolar wash samples from equids (Ainsworth et al., 2002; 2003; Dyer et al., 1983). Additionally, some studies have found that the latent infection of mononuclear cells in blood is an important mechanism for viral persistence and dissemination (Gendelman et al., 1985; 1986).

Therefore, the aim of this study was compared the efficiency of the nested PCR technique to amplify EIAV gag gene sequence in DNA samples from PBMCs and BAW isolated from naturally infected horses.

\section{MATERIALS AND METHODS}

A nested Polymerase Chain Reaction (nPCR) amplifying a region of the gag gene of Equine Infectious Anemia Virus (EIAV) was developed for comparing the virus detection effectiveness in Peripheral Blood Mononuclear Cells (PBMC) and Bronchoalveolar Wash (BAW) samples from 57 naturally infected horses accredited by the Ministry of Agriculture in Minas Gerais state, Brazil. Blood samples from all animals were positive for EIAV in Agar Gel Immunodiffusion Assay (AGID) and Equine Dermal cells (ED) infected and non infected by

Corresponding Author: Elizangela Maira Dos Santos, Department of Preventive Veterinary Medicine, Veterinary School, Federal University of Minas Gerais, UFMG, 30123-970, Belo Horizonte, MG, Brazil Tel: +55-31-34092127/+55-31-85246762 
EIAV was used as negative and positive control, respectively. Genomic DNA was isolated from BAW and PBMCs samples using QIAamp DNA Mini Kit (Qiagen), according to the manufacturer's instructions. The specific primers pair (5'-cgacatccgtaaggacctgt-3') and (5'-gtggacaatgaggccagaat-3') were designed to amplified $\beta$-actin reference gene sequence fragment with 191 base pairs and for EIAV gag gene amplification we used the flanking primers 636 (5'ccattgctggaagatgtaac-3') and 1399 (5'tgcgttctgaatagtcagtg- $\left.3^{\prime}\right)$ and the internal primers 854 (5'-ggctggaaacagaaatttta-3') and 1262 (5'aggtttccaatcatcact-3'), amplifying a 408 base pair fragment, using the protocol from the Platinum ${ }^{\circledR}$ Taq DNA Polymerase kit (Invitrogen). The actin and gag amplified fragments was observed under UV light, after agarose gel electrophoresis at $1 \%$ and stained by ethidium bromide. To confirm the analytical specificity of the amplicon, its sequence was determined.

\section{RESULTS}

Results demonstrated $89 \%$ (51/57) of gag gene amplification in PBMCs samples and only 47\% (27/57) of gag gene amplification in BAW samples (Fig. 1 and 2). The reference gene $\beta$-actin were amplified in all samples.

The nested PCR assay developed in the present study detected more EIAV positive samples in PBMCs than in BAW, indicating PBMCs as a reliable source for EIAV diagnosis. To examine the agreement between the tests, Kappa statistical analysis was performed using the Win Episcope 2.0 software (Table 1). The results from the sequence analysis of the $408 \mathrm{bp}$ fragment amplified by nPCR showed that it corresponded to the gag region of EIAV.

\section{DISCUSSION}

According to these results PBMCs are more suitable for proviral DNA amplification by nPCR than BAW. In addition, six DNA samples from PBMCs showing positive serological results were negative in the nPCR and these negative results could be due to insufficient number of infected cells or to a low number of provirus copies per cell (Eaves et al., 1994; Reichel et al., 1998), as a consequence of the end of the viremic episodes. Additionally, Monocytes infected by EIAV appear cyclically in the bloodstream and their appearance is associated with viremic episodes (O'Rourke et al., 1991). Moreover, as it was not possible to determine the stage of the disease by the time the animals were killed, they could be in an asymptomatic stage with viremy in plasma and the provirus copy inside the PBMCs may notbedetected (Oaks et al., 1998).

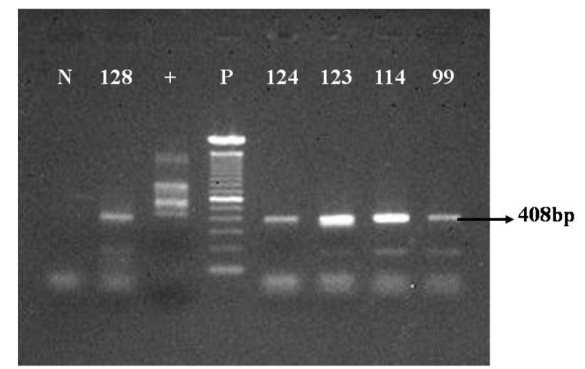

Fig. 1: Agarose gel 1\% from gag nPCR. N: negative control; +: positive control; 128, 124, 123, 114 and 99: EIAV positive samples from BAW; P: DNA ladder (100 bp-Invitrogen)

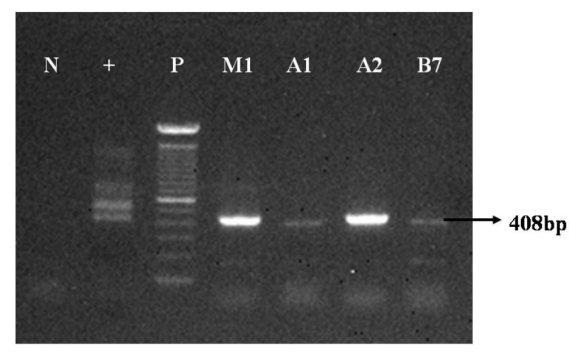

Fig. 2: Agarose gel 1\% from gag nPCR. N: negative control; +: positive control; M1, A1, A2 and B7: EIAV positive samples from PBMCs; P: DNA ladder (100 bp-Invitrogen)

Table 1: Comparison results of gag nPCR in DNA samples from PBMCs and BAW with the respective value for kappa

\begin{tabular}{lllrr}
\hline & & BAW nPCR gag & \\
& & ------------ & \\
& Positive & Negative & Total \\
\hline PBMC & Positive & 26 & 25 & 51 \\
nPCR gag & Negative & 1 & 5 & 6 \\
Total & & 27 & 30 & 57 \\
KAPPA & 0,124 & & & \\
\hline
\end{tabular}

On the other hand, the high number of negative results in BAW samples indicates that there may be a low number of provirus copies or insufficient numbers of cells containing the provirus. These results are contrary to those described earlier, that indicate tissue macrophages are the main cells involved in viral replication during the various phases of the disease and that less than $1 \%$ of viral load is found in peripheral monocytes (Harrold et al., 2000; Rice et al., 1989). Besides, the viral copies may be in a transition process from blood monocytes to tissue macrophages where occurs viral replication (Oaks et al., 1998; Sellon et al., 1992). Such transition may compromise the efficiency of the nPCR assay to detect EIAV sequences in DNA samples from BAW. 


\section{CONCLUSION}

According to PBMC and BAW gag PCR results, it can be concluded that PBMCs samples are more suitable and reliable source for EIAV diagnosis by nested PCR comparing with BAW samples from the same animals.

\section{ACKNOWLEDGEMENT}

This study was approved by the Ethics Committee of Veterinary Medical School (Department of Preventive Veterinary Medicine) at the Universidad Federal de Minas Gerais (UFMG) in Brazil. The authors wish to thank the Federal Sanitary Agents: Valmir Tunala and Jean Felipe Celestino Gouhie, Dr. Bongy Meira for their cooperation in obtaining the samples and Fapemig and CNPq for financial support.

\section{REFERENCES}

Ainsworth, D.M., J.A. Appleton, D.F. Antczak, M.A. Santiago and G. Aviza 2002. IgG antibody responses to an inhaled antigen in horses with "heaves" (recurrent airway obstruction). Vet. Immunol. Immunopathol., 84: 169-180.

Ainsworth, D.M., G. Grunig, M.B. Matychak, J. Young and B. Wagner et al., 2003. Recurrent Airway Obstruction (RAO) in horses is characterized by IFN-gamma and IL-8 production in bronchoalveolar lavage cells. Vet. Immunol. Immunopathol., 96: 83-91.

Alvarez, I., G. Gutierrez, E. Ostlund, M. Barrandeguy and K. Trono, 2007. Western blot assay using recombinant p26 antigen for detection of equine infectious anemia virus-specific antibodies. Clin. Vaccine Immunol., 14: 1646-1648.

Dyer, R.M., H.D. Liggitt and R.W. Leid, 1983. Isolation and partial characterization of equine alveolar macrophages. Am. J. Vet. Res., 44: 237984. PMID: 6660628

Eaves, F.W., J.B. Molloy, C.K. Dimmock and L.E. Eaves, 1994. A field evaluation of the polymerase chain reaction procedure for the detection of bovine leukaemia virus proviral DNA in cattle. Vet. Microbiol., 39: 313-321. PMID: 8042277

Gendelman, H.E., O. Narayan, S. Molineaux, J.E. Clements and Z. Ghotbi, 1985. Slow, persistent replication of lentiviruses: Role of tissue macrophages and macrophage precursors in bone marrow. Proc. Natl. Acad. Sci. USA., 82: 7086-7090. PMID: 2996004
Gendelman, H.E., O. Narayan, S. Kennedy-Stoskopf, P.G. Kennedy and Z. Ghotbi et al., 1986. Tropism of sheep lentiviruses for monocytes: Susceptibility to infection and virus gene expression increase during maturation of monocytes to macrophages. J. Virol., 58: 67-74. PMID: 3005660

Harrold, S.M., S.J. Cook, R.F. Cook, E.K. Rushlow and C.J. Issel et al., 2000. Tissue sites of persistent infection and active replication of equine infectious anemia virus during acute disease and asymptomatic infection in experimentally infected equids. J. Virol., 74: 3112-3121. PMID: 10708426

Issel, C.J. and R.F. Cook, 1993. A review of techniques for the serologic diagnosis of equine infectious anemia. J. Vet. Diagn. Invest., 5: 137-141. PMID 8385498

Langemeier, J.L., S.J. Cook, R.F. Cook, K.E. Rushlow and R.C. Montelaro et al., 1996. Detection of equine infectious anemia viral RNA in plasma samples from recently infected and long-term inapparent carrier animals by PCR. J. Clin. Microbiol., 34: 1481-1487. PMID: 8735102

Maury, W., 1994. Monocyte maturation controls expression of equine infectious anemia virus. J. Virol., 68: 6270-6279. PMID 8083967

Oaks, J.L., T.C. McGuire, C. Ulibarri and T.B. Crawford, 1998. Equine infectious anemia virus is found in tissue macrophages during subclinical infection. J. Virol., 72: 7263-7269. PMID: 9696821

O’Rourke, K.I., M.L. Besola and T.C. McGuire, 1991. Proviral sequences detected by polymerase chain reaction in peripheral blood cells of horses with equine infectious anemia lentivirus. Arch. Virol., 117: 109-119. PMID: 1848747

Reichel, M.P., K.M. Tham, S. Barnes and R. Kittelberger, 1998. Evaluation of alternative methods for the detection of bovine leukaemia virus in cattle. N. Z. Vet. J., 46: 140-146. PMID: 16032038

Rice, N.R., A.S. Lequarre, J.W. Casey, S. Lahn and R.M. Stephens et al., 1989. Viral DNA in horses infected with equine infectious anemia virus. J. Virol., 63: 5194-5200. PMID: 2555550

Sellon, D.C., S.T. Perry, L. Coggins and F.J. Fuller, 1992. Wild-type equine infectious anemia virus replicates in vivo predominantly in tissue macrophages, not in peripheral blood monocytes. J. Virol., 66: 5906-5913. PMID: 1382143

Sellon, D.C., K.M. Walker, K.E. Russell, S.T. Perry and P. Covington et al., 1996. Equine infectious anemia virus replication is unregulated during differentiation of blood monocytes from acutely infected horses. J. Virol., 70: 590-594. PMID: 8523576 